\title{
Technological Possibilities of the Carbide Tools Application for Precision Machining of WCLV Hardened Steel
}

\author{
Marcin Grabowski', Józef Gawlik' , Joanna Krajewska-Śpiewak', \\ Sebastian Skoczypiec ${ }^{1}$, Piotr Tyczyński² \\ 1 Chair of Production Engineering, Cracow University of Technology, Cracow, Poland \\ 2 Limatherm S.A., ul. Tarnowska 1, 34-600 Limanowa, Poland \\ * Corresponding author's e-mail: marcin.grabowski@pk.edu.pl
}

\begin{abstract}
Precision milling of free (curved) surfaces with the use of monolithic milling cutters is used in the production of hardened steel elements such as dies, molds, or press tools. Precision milling processes are carried out with the following milling parameters: axial cutting depth ap $<0.3 \mathrm{~mm}$, cutting width ae $<0.5 \mathrm{~mm}$ and the required machining accuracy below $40 \mu \mathrm{m}$. The quality of the obtained surfaces in injection molds is directly transferred to the quality of the molded part. One of the key criteria for the manufactured elements is the surface quality which is mainly assessed by the roughness parameters. Due to the use of carbide tools high reliability and quality of machining is obtained which allows to eliminate the grinding process. In precision milling processes, due to the very small radius of the cutting edge and the cross-sections of the cutting layers, the conditions that must be met for the decohesion process to occur are fundamentally diff erent from macro-scale. The minimum value range of $a p$ and ae parameters was determined in a carried-out experiment, which allows for stable and repeatable machining. The tests were carried out with double-edge shank cutters with a diameter of $6 \mathrm{~mm}$ on a workpiece made out of WCVL hardened steel 45-47 HRC. Recommended machining conditions have been defi ned to ensure the required technological quality of the surface layer. The research was fi nanced under the research project POIR.01.01.01-000890/17 co-fi nanced by the European Union from the European Regional Development Fund.
\end{abstract}

Keywords: precision milling, WCLV steel, carbide tools.

\section{INTRODUCTION}

The minimal thickness of the cutting layer mainly depends on properties of the workpiece and tool material as well as from geometry of the tool. Some special techniques of reducing the thickness of the cutting layer can be used in case of the materials with limited ability to chip formation. In this aspect the changes of the thermodynamic conditions like cutting temperature and stress in the workpiece should be considered. This is confirmed by the results of wear tests of tungsten carbide inserts with a special texture on the rake face [1].

Based on the performed cutting tests of AISI 1045 steel, the authors [2] found that the surface roughness increases with increasing feed (which is an obvious conclusion) and depth of cut and decreases with decreasing cutting speed. Finishing treatment is carried out with the minimum possible cross-sections of the cutting layer. Their value is strongly dependent on the physical properties of the workpiece material and the kinematic of cutting parameters. The goal of this research is determination of the minimum thickness of the cutting layer $[3,5,7]$.

The quality of pressure-cast products largely depends on the condition of the surfaces layer of the dies, assessed, among others, by roughness indicators. In the paper the precise milling process of dies made of WCLV alloy tool steel with hardness of 45-47 HRC was analyzed. Precise 
finishing machining of hardened surfaces requires application of carbide-tipped tools. The occurrence of decohesion process depends on the cutting parameters, however the cutting edge radius of a tool and the cross-section of the cutting layer are crucial. This is confirmed by the research presented in the following works $[4,8,10]$.

Ensuring the proper stiffness of the tool and tool holder system also plays an important role. Change in the stiffness of spherical cutters by the change of the extension length from the holder has a significant impact on the displacement of the working part of the cutter. This directly affects the value of the vibration amplitude and thus also the roughness parameters of the machined surface [6]. In paper [9] authors emphasize that the production of dies requires high rigidity of machine tools and technological devices - mainly spindles and tool holders.

The condition of the surface layer of the working surfaces of dies in the process of their exploitation plays an important role in terms of their reliability and repeatable quality assurance. Fatigue tests of WCLV steels show that during the operation of technological equipment at elevated temperatures, e.g., forging tools, interactions between changing temperature, variable load and the participation of oxidation and abrasive wear processes are observed [11].

Precision machining of difficult-to-cut materials can be supported by the electrochemical digestion process in the hybrid machining technology [12].The surfaces of the injection mold, especially the stamp and die surfaces, are exposed to cyclical cooling and heating. These phenomena adversely affect the formation of variable thermal stresses in the material and are the cause of formation of mesh of cracks over time, which ultimately leads to the withdrawal of the mold from further use. The proper selection of both the material and its shaping technology is a key aspect in the adequate functioning of the injection mold. Due to the high cost of production, the durability of the injection mold is important considering the profitability of production.

Precision machining of curvilinear surfaces with the use of monolithic tools is increasingly used in the production of machine, tools and device elements, where the main aspect is to obtain high-quality surfaces, in most cases determined by the roughness parameter. The production of injection molds, dies and stamping dies made of steel with increased mechanical properties should be distinguished as an example of such elements. One of the leading shaping operations in the technological process of manufacturing injection molds is the milling process. One can state that the main advantage of precision milling of sculptured surfaces is the possibility to eliminate EDM (Electric Discharge Machining) or to replace finishing processes such as grinding. Due to the specificity of the injection mold manufacturing process EDM or grinding are difficult or in some cases impossible to perform.

Due to the complex shape of the manufactured elements (curvilinear surfaces), in most cases, obtaining the required surface quality is possible only through the use of precision milling. It requires the application of appropriate parameters, which are characteristic for this type of processes. Additionally, high requirements - machining accuracy below $40 \mu \mathrm{m}$ are possible to obtain only with appropriately selected high static and dynamic stiffness of the machine tool (machine tool - holder - workpiece - tool system). For injection molds, the quality of the obtained surfaces is associated with the quality of the molded piece, which explains the necessity to apply high requirements regarding the geometric product specification (GPS).

The obtained surface quality which is determined by the roughness index, is one of the key criteria for the manufactured elements. It is mainly the result of process parameters such as:

- cutting tool geometry (rake angle, cutting edge radius);

- cutting parameters (depth of cut, tool feed, cutting speed, width of cut) and

- properties of the workpiece.

This article present the results of laboratory and industrial tests of WCLV hardened steel samples after finishing treatment with carbide end mills.

\section{MATERIALS AND METHODS}

Below there are the results of the laboratory and industrial tests of WCLV hardened steel milling. Milling tests were carried out according to the ZIG strategy. They can be the basis for the selection of the recommended parameters for the precise machining of hardened dies made of WCLV steel with the use of end mills with sintered carbide cutting edge. The WCLV hot worked alloy tool steel (1.2344) is intended 
Table 1. Chemical composition of WCLV steel [\%]

\begin{tabular}{|c|c|c|c|c|c|}
\hline $\mathrm{C}$ & $\mathrm{Mn}$ & $\mathrm{Si}$ & $\mathrm{P}$ & $\mathrm{S}$ & $\mathrm{Cr}$ \\
\hline $0.35-0.45$ & $0.2-0.5$ & $0.8-1.2$ & $\max 0.03$ & $\max 0.03$ & $4.5-5.5$ \\
\hline $\mathrm{Ni}$ & $\mathrm{Mo}$ & $\mathrm{W}$ & $\mathrm{V}$ & $\mathrm{Co}$ & $\mathrm{Cu}$ \\
\hline $\max 0.35$ & $1.2-1.5$ & $\max 0.3$ & $0.8-1.1$ & $\max 0.3$ & $\max 0.3$ \\
\hline
\end{tabular}

Table 2. Strength parameters of WCLV steel [11]

\begin{tabular}{|l|c|c|c|}
\hline \multirow{2}{*}{ Parameters } & \multicolumn{3}{|c|}{ Values of selected parameters at different } \\
\cline { 2 - 4 } & $20^{\circ} \mathrm{C}$ & $30^{\circ} \mathrm{C}$ & $60^{\circ} \mathrm{C}$ \\
\hline $\mathrm{R}_{\mathrm{m}}[\mathrm{MPa}]$ & 1778 & 1570 & 1041 \\
\hline $\mathrm{R}_{\mathrm{p} 0.2}[\mathrm{MPa}]$ & 1528 & 282 & 913.6 \\
\hline $\mathrm{A}_{12.5}[\%]$ & 26.9 & 29.8 & 23.4 \\
\hline $\mathrm{Z}[\%]$ & 49.8 & 55.4 & 52.1 \\
\hline $\mathrm{R}_{\mathrm{u}}[\mathrm{MPa}]$ & 2513 & 2519 & 1137 \\
\hline $\mathrm{E}[\mathrm{MPa}]$ & 207.02 & 198.69 & 126.91 \\
\hline
\end{tabular}

for pressure die casting molds of aluminum, magnesium and zinc alloys. It is characterized by high hardenability, resistance to tempering, the ability to work at high temperatures and a low tendency to the formation of a surface mesh of cracks. Due to the use of alloying elements, such as chromium and silicon, this steel is characterized by increased resistance to oxidation, increased high-temperature and fatigue strength. It is used in the production of hot working blades, die inserts for presses and forging machines, screws, dies, plastic molds, punches, spindles and copper rolling rolls. Chemical composition of WCLV steel is presented in Table 1. Table 2 shows selected properties of the material at different temperatures obtained from the tensile test [11].
The experimental tests were carried out on a test plate with dimensions of $170 \times 50 \times 20 \mathrm{~mm}$ (Figure 1). Since the research involved a precision milling process, it was necessary to prepare the test specimens. One of the main criteria was to maintain the parallelism of the machined surfaces within a tolerance of $0.05 \mathrm{~mm}$. This parallelism was achieved by grinding process. In addition, after the specimen was clamped in a vice, the testes surface was subjected to milling with a milling head. The milling head parameters were chosen from the center of the test plan. This ensured that the prepared surface was parallel to the tool's working surface (XY surface of the work table). The main goal of the test was to determine the influence of the parameters of the precision milling process and the cutting edge geometry on the properties of the machined surface layer. The experimental studies were conducted in accordance with the experimental planning theory [13]. It enables the determination of analytical polynomial relationships in the form of power formulas which are often used to describe the relationship between machining parameters (input values, variables) and the output values (e.g., surface roughness, tool life).

The tool operated in a ZIG strategy, where the red arrow indicates the direction of the working motion and the green arrow indicates the idle (return) motion.
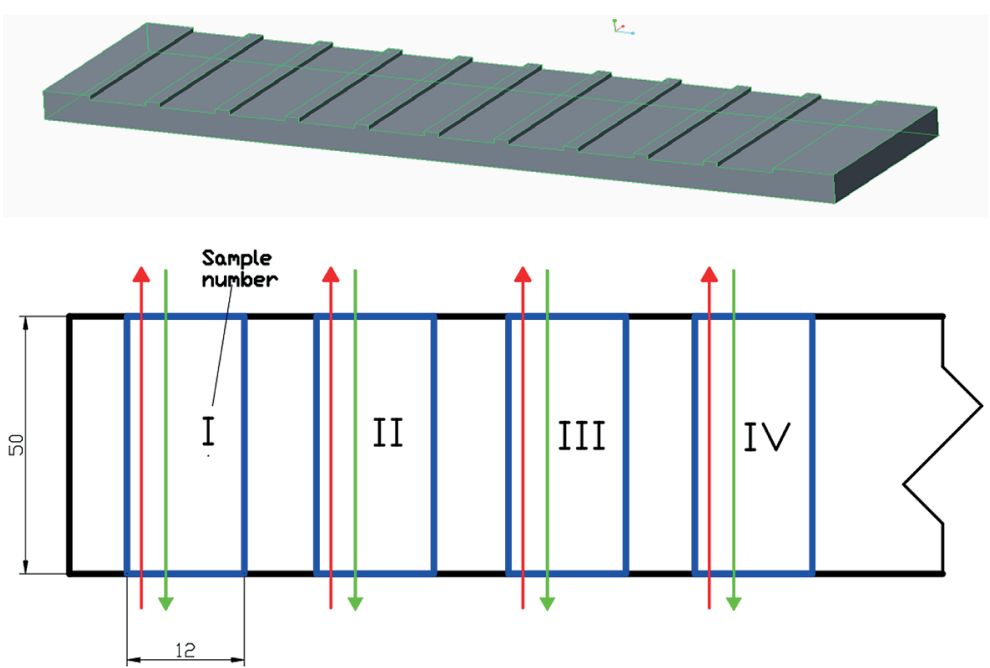

Fig. 1. Test sample with marked test areas 
Table 3. Cutting parameters of the finishing process for monolithic end milling cutter

\begin{tabular}{|c|c|c|}
\hline Cutting tools & \multicolumn{2}{|c|}{ Cutting parameters } \\
\hline \multirow{3}{*}{$\begin{array}{c}\text { Cutters with carbide } \\
\text { cutting edge }- \text { diam- } \\
\text { eter of } \mathrm{mm}\end{array}$} & $n[\mathrm{rpm}]$ & $8000-9000-10000$ \\
\cline { 2 - 3 } & $f[\mathrm{~mm} / \mathrm{min}]$ & $1000-1200-1400$ \\
\cline { 2 - 3 } & $a_{p}[\mathrm{~mm}]$ & $0.02-0.04-0.06$ \\
\cline { 2 - 3 } & $a_{e}[\mathrm{~mm}]$ & $0.02-0.04-0.06$ \\
\hline
\end{tabular}

The tests were carried out in two series on the FELLER U600, five-axis milling center. In the first series, the influence of the cutting speed, feed speed and cutting edge geometry on the surface roughness was investigated. The surface roughness was measured in two directions: perpendicular and parallel to the feed direction of the tool feed. The milling depth and width were assumed as constant parameters during machining. In the second series, the influence of the cutting edge geometry, depth of cut and the width of cut on the surface roughness was investigated. Cutting speed and the feed rate were constant. The surface roughness $R a<$ $0.63 \mu \mathrm{m}$ and the machining accuracy of $0.01 \mathrm{~mm}$ were assumed as the milestones of the precision milling process for the first and second series. StatSoft Statistica was used to analyze the research results. A polynomial regression model with interactions was selected as the function of the research object. The regression coefficients, the adequacy of the function and the significance of the polynomial coefficients were determined. Table 4 shows the individual values for research plans.

Table 4. The influence of machining parameters $(n, f$ and $y)$ on the values of surface roughness - carbide tool $(\mathrm{D}=$ $6 \mathrm{~mm})$, for constant parameters $a_{p}=0.04 \mathrm{~mm}, a_{e}=0.04 \mathrm{~mm}$

\begin{tabular}{|c|c|c|c|c|c|c|c|}
\hline \multirow{2}{*}{ No. } & \multirow{n}{n}{} & $\mathrm{f}$ & $\mathrm{f}$ & $\mathrm{Y}{ }^{\circ}$ & \multicolumn{2}{|c|}{ Perpendicular direction of the cutting edge } & \multicolumn{2}{|c|}{ Parallel direction of the cutting edge } \\
\cline { 5 - 8 } & {$[\mathrm{mm} / \mathrm{min}]$} & $($ rake angle $)$ & $\mathrm{R}_{\mathrm{a}}$ & $\mathrm{R}_{\mathrm{z}}$ & $\mathrm{R}_{\mathrm{a}}$ & $\mathrm{R}_{\mathrm{z}}$ \\
\hline 1 & 8000 & 1000 & 0 & 0.33 & 2.3 & 0.22 & 1.35 \\
\hline 2 & 10000 & 1000 & 0 & 0.42 & 2.58 & 0.18 & 1.12 \\
\hline 3 & 8000 & 1400 & 0 & 0.44 & 2.9 & 0.22 & 1.74 \\
\hline 4 & 10000 & 1400 & 0 & 0.35 & 2.29 & 0.24 & 1.6 \\
\hline 5 & 8000 & 1000 & 5 & 0.34 & 2.13 & 0.22 & 1.36 \\
\hline 6 & 10000 & 1000 & 5 & 0.32 & 2.13 & 0.21 & 1.23 \\
\hline 7 & 8000 & 1400 & 5 & 0.4 & 2.44 & 0.39 & 2.42 \\
\hline 8 & 10000 & 1400 & 5 & 0.31 & 2.05 & 0.21 & 1.74 \\
\hline 9 & 9000 & 1200 & 3 & 0.41 & 2.63 & 0.26 & 1.6 \\
\hline 10 & 9000 & 1200 & 3 & 0.51 & 3.16 & 0.21 & 1.31 \\
\hline 11 & 9000 & 1200 & 3 & 0.3 & 2.15 & 0.18 & 1.24 \\
\hline
\end{tabular}

a)

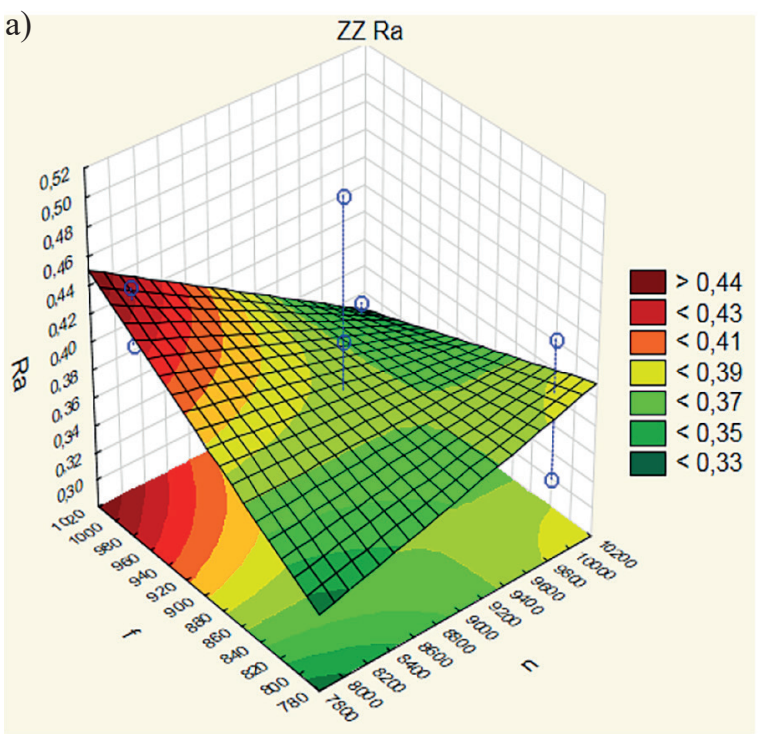

b)

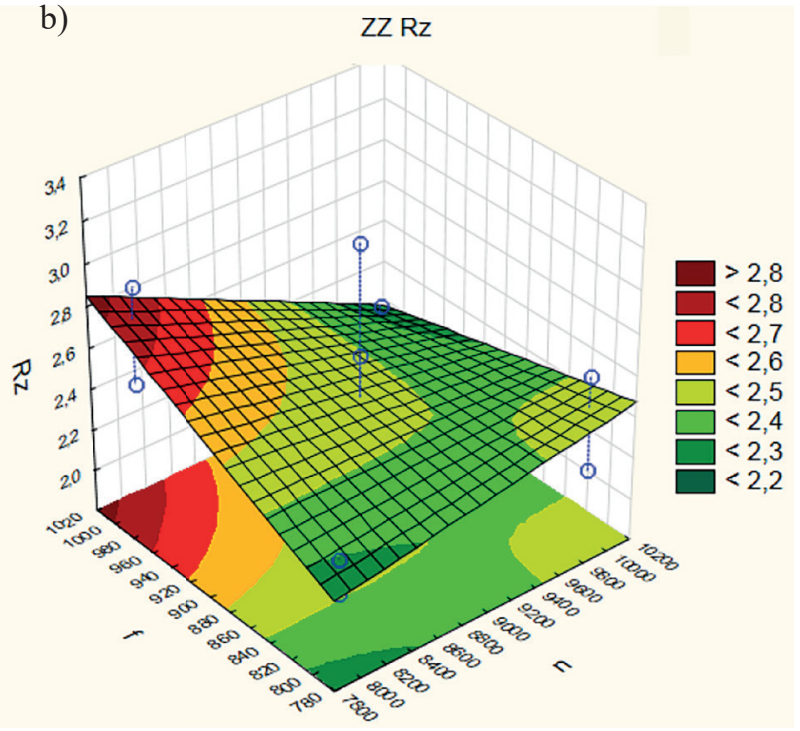

Fig. 2. The response surface plots for $R a$ and $R z$ parameters measured in the perpendicular direction for constant parameters $a_{p}=0.04 \mathrm{~mm}, a_{e}=0.04 \mathrm{~mm}$ 


\section{Analysis of the results}

The multinomial regression model with interactions describing the surface roughness $R a$ measured in the perpendicular direction for the above research plan is represented by the following relationship:

$R_{a}=-0.0275 \cdot n+0.0225 \cdot f-42.5 \cdot \gamma \cdot 10^{-3}-$ $-0.0625 \cdot n \cdot f-0.027500 \cdot \gamma \cdot n+0.0025 \cdot \gamma \cdot f(1)$

In relation to the input parameters the response surface plots are shown in Figure 2 which were developed on the basis of the performed tests. The values of roughness for the whole tests made in the research plan for the second series are presented in Table 5. The regression model of the surface roughness measured in the parallel direction for the above research plan is represented by the following relationship:

The response surface plots for selected input parameters used for the second series are presented in Figure 3.

The surfaces obtained during the tests were additionally subjected to the qualitative analysis. Photographs taken with an OLYMPUS microscope were used to complete the quantitative analysis in the form of a roughness measurement. In the Figures 4 and 5 the photographs of the machined surfaces for selected research plan at 2.5 times and 10 times magnification are presented.

Injection molds are intended for mass production, therefore their fatigue strength, reliability

Table 5. The influence of machining parameters ( $a e$, ap and y) on the values of surface roughness - carbide tool (D $=6 \mathrm{~mm}$ ), with constant parameters $n=9000 \mathrm{rpm}, f=1200 \mathrm{~mm} / \mathrm{min}$

\begin{tabular}{|c|c|c|c|c|c|c|c|}
\hline \multirow{2}{*}{ Np. } & $\begin{array}{c}\mathrm{a}_{\mathrm{p}} \\
{[\mathrm{mm}]}\end{array}$ & $\begin{array}{c}\mathrm{a}_{\mathrm{e}} \\
{[\mathrm{mm}]}\end{array}$ & $\begin{array}{c}\mathrm{Y}^{\circ} \\
\text { (rake angle) }\end{array}$ & \multicolumn{2}{|c|}{ Perpendicular direction of the cutting edge } & \multicolumn{2}{|c|}{ Parallel direction of the cutting edge } \\
\cline { 5 - 8 } & & $\mathrm{Ra}$ & $\mathrm{Rz}$ & $\mathrm{Ra}$ & $\mathrm{Rz}$ \\
\hline 1 & 0.02 & 0.02 & 0 & 0.32 & 2.8 & 0.19 & 1.34 \\
\hline 2 & 0.06 & 0.02 & 0 & 0.33 & 2.37 & 0.22 & 1.36 \\
\hline 3 & 0.02 & 0.06 & 0 & 0.38 & 2.51 & 0.22 & 1.44 \\
\hline 4 & 0.06 & 0.06 & 0 & 0.5 & 2.86 & 0.23 & 1.3 \\
\hline 5 & 0.02 & 0.02 & 5 & 0.33 & 2.37 & 0.22 & 1.25 \\
\hline 6 & 0.06 & 0.02 & 5 & 0.33 & 2.37 & 0.19 & 1.47 \\
\hline 7 & 0.02 & 0.06 & 5 & 0.53 & 4.35 & 0.27 & 1.53 \\
\hline 8 & 0.06 & 0.06 & 5 & 0.45 & 2.98 & 0.21 & 1.31 \\
\hline 9 & 0.04 & 0.04 & 3 & 0.39 & 2.5 & 0.22 & 1.24 \\
\hline 10 & 0.04 & 0.04 & 3 & 0.34 & 2.53 & 0.21 & 1.54 \\
\hline 11 & 0.04 & 0.04 & 3 & 0.53 & 3.71 & 0.24 & 1.39 \\
\hline
\end{tabular}

a)

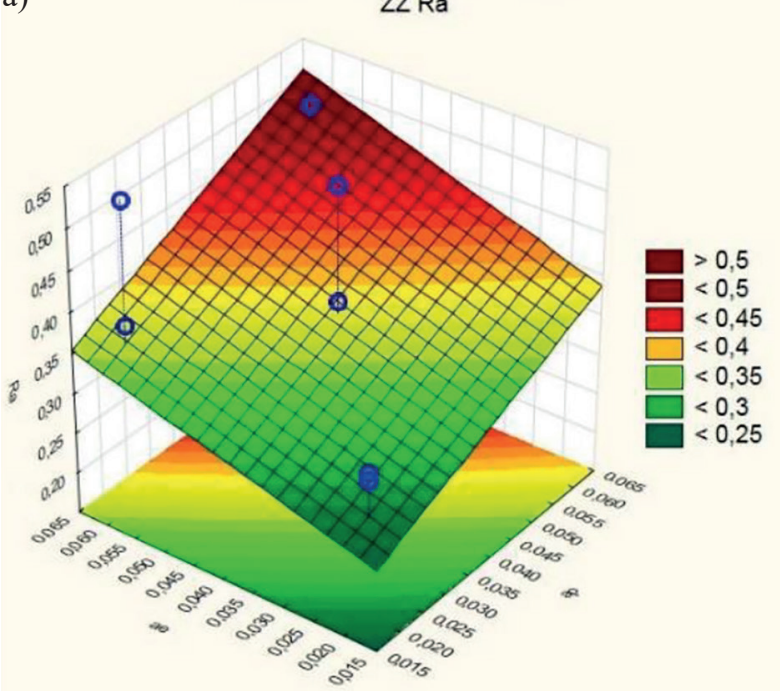

b)

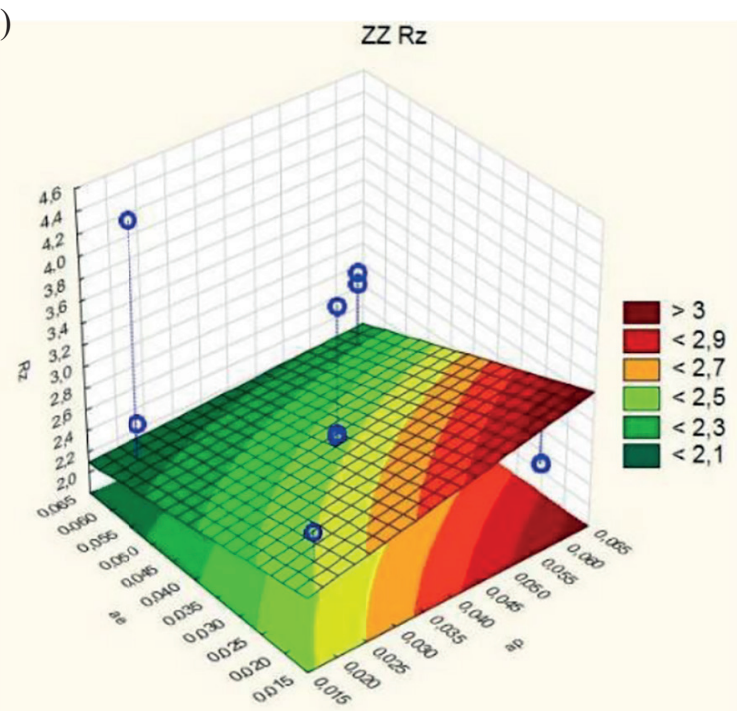

Fig. 3. The response surface plots for $R a$ and $R z$ parameters measured in the perpendicular direction with constant parameters $n=9000 \mathrm{rpm}, f=1200 \mathrm{~mm} / \mathrm{min}$ 
a)

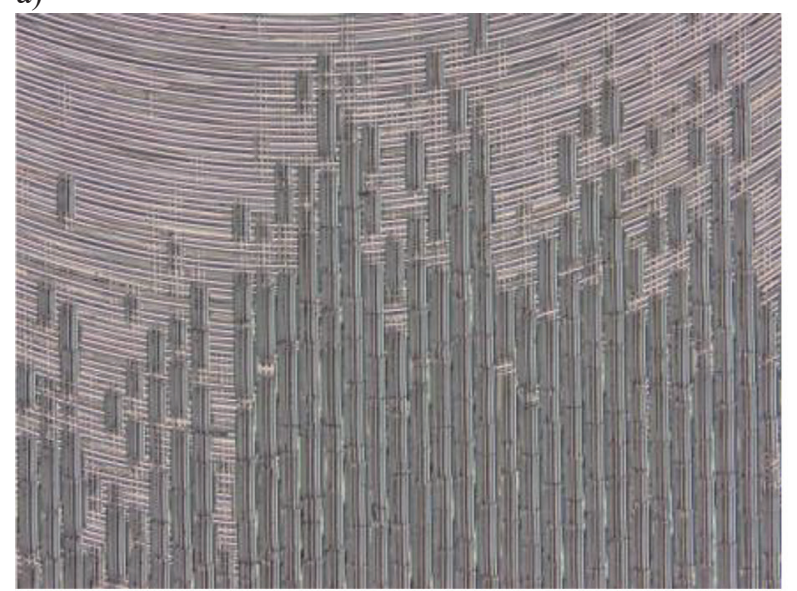

b)

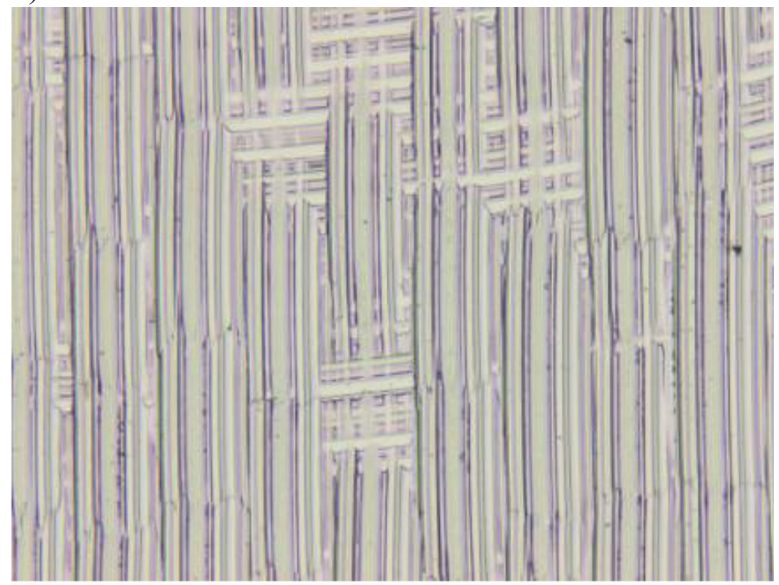

Fig. 4. The surface of the workpiece after milling with a carbide tool for the third case of the second series, $a_{p}=0.02[\mathrm{~mm}], a_{e}=0.06[\mathrm{~mm}], n=9000 \mathrm{rpm}, f=1200 \mathrm{~mm} / \mathrm{min}$ a) at 2,5 times magnification, b) at 10 times magnification.
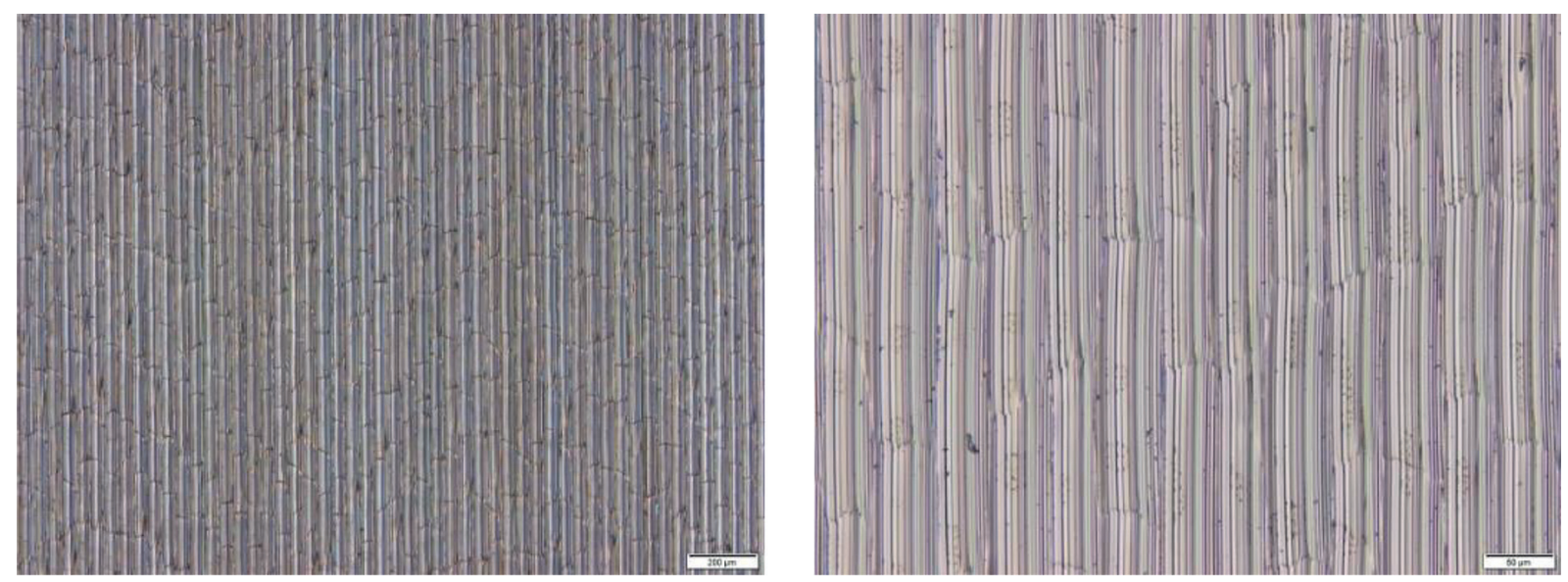

Fig. 5. The surface of the workpiece after milling with a carbide tool for the third system of the second series, $n=11000[\mathrm{rpm}], f=1400[\mathrm{~mm} / \mathrm{min}], a_{p}=0.04[\mathrm{~mm}], a_{e}=0.04[\mathrm{~mm}]$

a) at 2.5 times magnification, b) at 10 times magnification

and operating time are very important. Each manufacturing defect can significantly affect the life of the mold. Metallographic tests were carried out in order to determine the impact of the precision milling process on the possibility of structural changes in the workpiece. These tests were carried out for one sample from the first and the second series. The lowest surface roughness was used as the sample selection criterion. Obtained results of these tests are shown in Figure 6. No microstructural changes (such as hardening) of the workpiece were observed during carried out analysis of the metallographic specimens of elements created as a result of milling with carbide tools. On the other hand, the influence of the milling process on the formation of plastic deformations in the milling area was noticed.
The tests of metallographic specimens were carried out for sample number 11 of the plane perpendicular to the milling direction. The roughness value in the analyzed case was equal to $0.3 \mu \mathrm{m}$ for $R_{a}$ parameter and $2.15 \mu \mathrm{m}$ for $R_{z}$ parameter.

\section{CONCLUSIONS}

The efficiency of the precision milling process is an important factor that affects the cost of the entire injection mold manufacturing process. However, one can state that removal of very small allowances is associated with a decreased efficiency of cutting operation. Such case was the purpose of the presented in the paper investigation. The machining process should be carried 

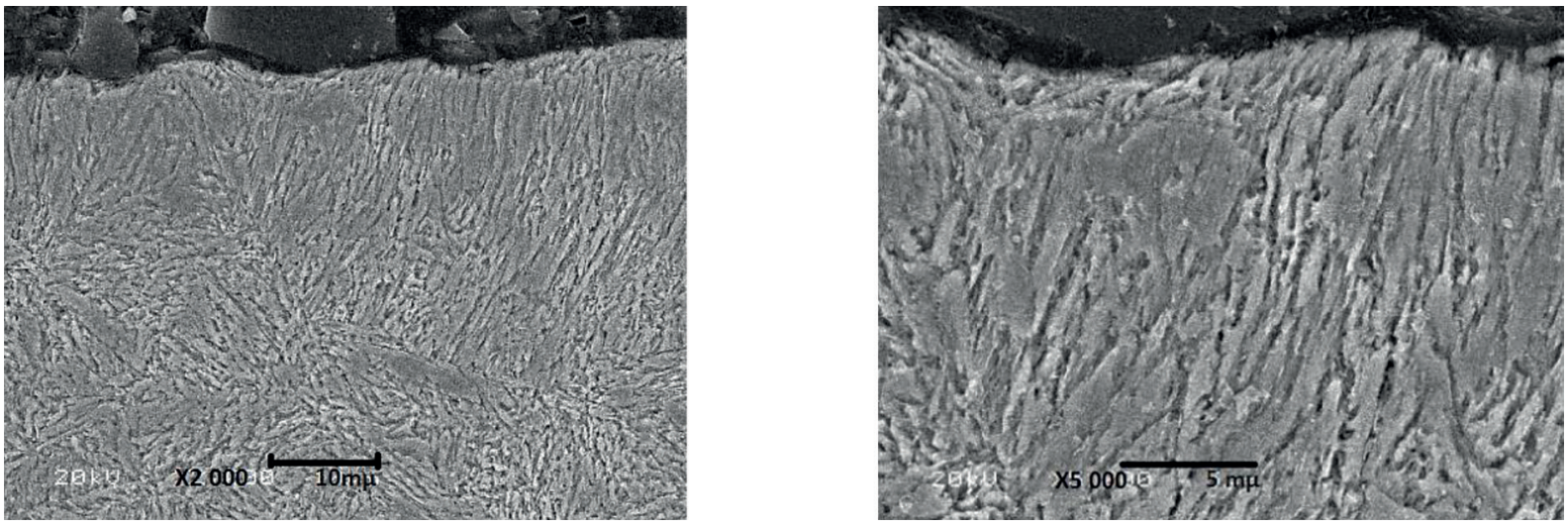

Fig. 6. Microstructure of the workpiece after milling with a carbide tool for the third system of the second series, $n=9000[\mathrm{rpm}], f=1200[\mathrm{~mm} / \mathrm{min}], a_{p}=0.04[\mathrm{~mm}], a_{e}=0.04[\mathrm{~mm}]$ in magnification at a) $\left.\times 2000 \mathrm{~b}\right) \times 5000$

out with parameters that allow the most efficient machining while maintaining the required surface quality. Based on the conducted experimental studies, the following conclusions can be drawn with regard to the finishing treatment of injection molds made of WCLV steel with a hardness of 45-47 HRC with carbide tools:

- for the entire examined ranges of variables $(a$, $\left.a_{e}, y, f, n\right)$ the surface roughness $R a$ was below the assumed level of $0.63 \mu \mathrm{m}$ for roughness measured in perpendicular and parallel to the feed direction,

- the increases in the cutting width (ae) causes a noticeable increase in the surface roughness $R a$ measured in both directions. In order to obtain a high surface quality associated with low roughness, small values of the cutting width should be used. Values ae in range of 0.02-0.04 $\mathrm{mm}$ are recommended. At this point it should be noted that the use of small cutting widths is directly related to the machining efficiency,

- increase of the depth of cut does not increase the roughness measured in the perpendicular direction. In the case of roughness measured in the parallel direction, a decrease in roughness can be observed with an increase of the depth of cut. It is recommended to use high values of the depth of cut (in the carried out research $a_{p}=0.06 \mathrm{~mm}$ ), which positively affects both the surface quality and the efficiency of the process,

- for low values of the rotational speed $(n=$ 8000-9000 rpm), the roughness Ra increases with the increase of the feed rate $f$. An increase in the tool rotational speed $(n=9000-10000$ $\mathrm{rpm})$ and feed $(f)$ has a positive effect on the improvement of the surface quality. Due to the efficiency of the process, it is recommended to use high values of rotational speed and feed ( $n$ $=10,000 \mathrm{rpm}, f=1,000 \mathrm{~mm} / \mathrm{min}$ ),

- the roughness value $(R a)$ measured in the parallel direction increases with the increase of the feed and the decrease of the rotational speed of the tool. It is recommended to use low feed rates $(f=800 \mathrm{~mm} / \mathrm{min})$ and high speeds $(n=10,000 \mathrm{rpm})$.

Based on the images in Figures 4 and 5, a qualitative assessment of the obtained surfaces was made. The machined surface is characterized by clear traces of milling. The process of chip formation in precision machining depends on the minimal thickness of the removing material, which forces the appropriate selection of the cutting tool with the smallest possible cutting edge radius. The carried out experimental studies of precision milling with carbide tools showed that the removal of very small sections of the cutting layer in the analyzed case, where $a_{p}=0.02 \mathrm{~mm}$ and $a_{e}=0.02 \mathrm{~mm}$ causes disturbances in the decohesion process, as shown in Figure 4.

\section{REFERENCES}

1. Darshan C., Singh P., Saini S. Comparative Evaluation of Untextured and Textured WC Inserts Under Dry and Near Dry Machining of C45 Steel. Int. Journal of General Engineering and Technology. 2017; 6(5): 1-16

2. Irfaan M., Temesgen A.D., Tsegay M.M. Application of Taguchi Method \& Anova in turning of AISI 1045 to improve surface roughness by Optimize cutting factor. American Journal of Engineering Research. 2015; 4(12): 120-125.

3. Krajewska-Śpiewak J., Gawlik J. A method for determination of the minimal thickness of the cutting 
layer during precision machining performed with the indexable cutting tools, Trans Tech Publications. Solid State Phenomena. 2017; 261: 50-57.

4. Nguyen T.D., Tran N.T., Hoang T.D., Nguyen N.T., Quy T.D., Thien N.V. Cutting Forces and Surface Roughness in Face-Milling of SKD61 Hard Stee, Strojniški vestnik. Journal of Mechanical Engineering. 2019; 65(6): 375-385. DOI:10.5545/svjme.2019.6057

5. Storch B., Tomkiewicz-Zawada A. Distribution of unit forces on the tool edge rounding in the case of finishing turning. Int J Adv Manuf Technol. 2012; 60: 453-461. DOI: 10.1007/s00170-011-3617-7

6. Twardowski P., Hamrol A., Znojkiewicz N., Wojciechowski S. An improved cutting force and surface topography prediction model in end milling. International Journal of Machine Tools and Manufacture. 2007; 47(7): 1263-1275. DOI: 10.1016/j.imachtools.2006.08.021

7. Wojciechowski S., Wiackiewicz M., Krolczyk G.M. Study on metrological relations between instant tool displacements and surface roughness during precise ball end milling. Measurement. 2018; 129: 686-694. DOI: 10.1016/j.measurement.2018.07.058

8. Wojciechowski S., Maruda R.W., Barrans S., Niesłony P., Krolczyk G.M. Optimisation of ma- chining parameters during ball end milling of hardened steel with various surface inclinations. Measurement. 2017; 111: 18-28. DOI: 10.1016/j. measurement.2017.07.20

9. Fallböhmer P., Rodrìguez C.A., Özel T., Altan T. High-speed Machining of Cast Iron and Alloy Steels for Die and Mold Manufacturing, Journal of Materials Processing Technology. 2000; 98 104-115.

10. Murugan Gopalsamy B., Mondal B., Ghosh S., Arntz K., Klocke F. Experimental investigations while hard machining of DIEVAR tool steel (50 HRC), Int J Adv Manuf. Technol. 2010; 51: 853869. DOI: 10.1007/s00170-010-2688-1

11. Hawryluk M., Dolny A., Mroziński S. Low cycle fatigue studies of WCLV steel (1.2344) used for forging tools to work at higher temperatures, Archives of Civil and Mechanical Engineering. 2018; 18(2): 465-478.

12. Grabowski M., Skoczypiec S., Wyszynski D. A Study on Microturning with Electrochemical Assistance of the Cutting Process. Micromachines. 2018; 9: 357. DOI: 10.3390/mi9070357

13. Irfaan M., Temesgen A.D., Tsegay M.M. Application of Taguchi Method \& Anova in turning of AISI 1045 to improve surface roughness by Optimize cutting factor. American Journal of Engineering Research (AJER). 2015; 4(12): 120-125. 